\title{
Jails: The New Frontier. HIV Testing, Treatment, and Linkage to Care After Release
}

\author{
Timothy P. Flanigan
}

Published online: 23 August 2013

(C) Springer Science+Business Media New York 2013

Jails represent a critical point for public health intervention within the criminal justice system. Characterized by rapid turnover, jails can serve as a window of opportunity for many interventions-including those designed to identify HIV infection among detainees, initiate or re-initiate HIV care and antiretroviral therapy (ART), and provide linkage to care after release. The most vulnerable within our communities pass through jails; incarceration transcends "risk categories". Addressing HIV within jails is not limited to interventions targeting one specific risk group. Men who have sex with men (MSM), high-risk heterosexuals, and those who have a history of injection drug use can all be found within jails, which make jails ideal settings through which to impact HIV within the community as a whole.

An estimated one in seven persons living with HIV/ AIDS leave a prison or jail each year [1], and over 11 million persons are admitted to jails annually [2]. While the majority of HIV programs within correctional facilities are based in prisons, as opposed to jails, the vast majority of incarcerated persons each year are detained only in jails and never have access to prison-based programs. Approximately $95 \%$ of inmates are released from jails each year with average lengths of stay often less than $72 \mathrm{~h}$, representing the challenge and importance of intervening within a rapidly closing window.

The papers included in this special issue of AIDS and Behavior demonstrate, as a whole, that HIV programming for jail detainees and releases can lead to positive outcomes-enhanced identification of HIV cases, engagement and retention in care, and improved clinical outcomes. The

T. P. Flanigan $(\bowtie)$

The Miriam Hospital, Alpert Medical School of Brown University, 164 Summit Avenue, Providence, RI 02906, USA

e-mail: TFlanigan@Lifespan.org
10 demonstration models funded through the HRSA/SPNS EnhanceLink initiative have shown that successful partnerships can be developed between community-based organizations, correctional systems, and/or health departments. Testing programs can be implemented, treatment can be initiated/reinitiated, and individuals can be linked to care in the community after release. Findings from the multisite evaluation of these models show the overall successes of the initiative, yet also highlight challenges that remain. Overall, these papers describe a population impacted by substance use, mental illness, unstable housing, lower educational attainment, and difficulties with health insurance; many of these factors were found to influence engagement in care and outcomes. However, services provided inside jail and in the community after release can make a difference. Engagement in care and viral suppression are possible and interventions appear to be cost-saving on a societal level. More specifically:

Richard Rapp et al. [3] discuss the limited evidencebase to date and the importance of adapting successful prison and community-based interventions. Alison Jordan et al. [4] provide a useful description of the model of care implemented for Rikers Island in New York City, where over $70 \%$ of HIV-infected persons released to the community are linked to primary care; this serves as an example for other jurisdictions.

Anne Spaulding et al. [5] provide an overview of the EnhanceLink project and demonstrate the feasibility of HIV testing in jail and provision of linkage services to enhance continuity of care. Over $80 \%$ of HIV-infected persons offered linkage and transitional services accepted program services. Matt Stein et al. 
[6] presents the baseline characteristics of the EnhanceLink cohort, highlighting a population impacted by mental illness, substance use, low educational attainment, and extensive involvement with the criminal justice system. Notably, $20 \%$ of male participants self-identified as homosexual or bisexual, and $65 \%$ of the cohort self-identified as AfricanAmerican, with African-Americans less likely to have health insurance or an HIV provider. Ehsan Chitsaz et al. [7] provide a detailed analysis of baseline substance use among the cohort, finding that polysubstance use is common among participants and that drug use severity is independently correlated with lower likelihood of having an HIV care provider, being prescribed ART, and adherence to treatment prior to incarceration. Ann Avery et al. [8] found that having insurance at baseline was a correlate of being in care and being adherent to care, while recent homelessness and high degrees of substance abuse were correlated with nonadherence to ART and being out of care. Chyvette Williams et al. [9] report that HIV-infected women in jails have a greater burden of illness and greater need. Compared to men, at baseline, women are more likely to be homeless, have more severe addiction problems, more chronic health conditions, and are less adherent to ART.

Jeannia $\mathrm{Fu}$ et al. [10] found that nearly one-third of the EnhanceLink cohort was reincarcerated within the 6-month follow-up period, with homelessness, major psychiatric diagnosis, and longer lifetime incarceration history associated with recidivism and health insurance post-release associated with a decreased likelihood of recidivism. Cristina Booker et al. [11] report that approximately three-quarters of those enrolled in the cohort received services in the first 30 days after release. The critical finding is that services provided inside jail matter! Factors associated with linkage included HIV or medication education inside jail, discharge plans completed upon release, and stable housing. As described by Alexei Zelenev et al. [12], transitions from homelessness to more stable housing were closely associated with a number of benefits to overall well-being, including reduction in substance use, decline in addiction severity, and improvements in mental health.

Finally, in two separate papers, Anne Spaulding et al. illuminate the key take-home messages for decision makers-viral suppression is achievable [13] and
EnhanceLink interventions appear to be cost-saving [14].

The success of the EnhanceLink initiative should represent the beginning of key program implementation nationwide. Routine HIV testing in jails, particularly in harder-hit communities, makes sense. Improvements in ART are so extraordinary and cost-effective that initiating or reinitiating treatment is a high priority. The time detainees spend in jail is just the beginning, as linking and re-engaging releasees to care in the community is of paramount importance. This is consistent with the National HIV/AIDS Strategy, which includes establishing a seamless system to link people with continuous and coordinated quality care [15].

Although many lessons have been learned from the EnhanceLink initiative, there remain unanswered questions and challenges. "One size fits all" approaches may not work; women are different from men and may require unique interventions to meet gender-specific needs. When dealing with homeless and/or unstably housed persons, treating HIV is very difficult when basic support (such as safe housing) is not in place. The national epidemic of substance abuse is at the root of many of the challenges, and improving substance use treatment within jails is necessary.

Six years ago, when the EnhanceLink demonstration models were first funded, experts believed routine HIV testing, treatment, and linkage to care among jail detainees was impossible due to the chaotic nature of jails, inmates' lives and the environment, and that structural constraints would be an insurmountable barrier for the application of the Seek, Test, Treat, and Retain paradigm within that setting. The following manuscripts demonstrate that this is NOT the case. In fact, these models for HIV testing and care can also be applied to other infectious diseases, including hepatitis $\mathrm{C}$ virus and sexually transmitted infections, which also are in need of appropriate intervention. Leaders in public health, HIV medicine, correctional health, and academia need to move forward-togethertoday-to address these ongoing challenges and improve the overall health of the community.

Acknowledgments The authors would like to acknowledge the financial support of HRSA/SPNS (H97HA08535) and NIH (P30AI042853 and P30DA013868).

\section{References}

1. Spaulding AC, Seals RM, Page MJ, Brzozowski AK, Rhodes W, Hammett TM. HIV/AIDS among inmates of and releasees from US correctional facilities, 2006: declining share of epidemic but persistent public health opportunity. PLoS One. 2009;4(11):e7558. 
2. Minton T. Jail inmates at mid-year 2012-statistical tables. US Department of Justice, Bureau of Justice Statistics; May 2012. NCJ 241264. Washington, DC. Available at: http://www.bjs.gov/ content/pun/pdf/jim12st.pdf.

3. Rapp RC, Ciomcia R, Zaller N, Draine J, Ferguson A, Cagey R. The role of jails in engaging PLWHA in care: from jail to community. AIDS Behav. 2012 Nov 16 (Epub ahead of print).

4. Jordan AO, Cohen LR, Harriman G, Teixeira PA, CruzadoQuinones J, Venters H. Transitional care coordination in New York City jails: facilitating linkages to care for people with HIV returning home from Rikers Island. AIDS Behav. 2012 Nov 6 (Epub ahead of print).

5. Spaulding AC, Booker CA, Freeman SH, et al. Jails, HIV testing, and linkage to care services: an overview of the enhancelink initiative. AIDS Behav. 2012 Oct 27 (Epub ahead of print).

6. Stein MS, Spaulding AC, Cunningham M, et al. HIV-positive and in jail: race, risk factors, and prior access to care. 2012 Oct 20 (Epub ahead of print).

7. Chitsaz E, Meyer JP, Krishnan A, et al. Contribution of substance use disorders on HIV treatment outcomes and antiretroviral medication adherence among HIV-infected persons entering jail. AIDS Behav. 2013 May 15 (Epub ahead of print).

8. Avery AK, Ciomcia RW, Lincoln T, et al. Jails as an opportunity to increase engagement in HIV care: findings from an observational cross-sectional study. AIDS Behav. 2012 Sep 28 (Epub ahead of print).
9. Williams CT, Kim S, Meyer J, et al. Gender differences in baseline health, needs at release, and predictors of care engagement among HIV-positive clients leaving jail. AIDS Behav. 2013 Jan 12 (Epub ahead of print).

10. Fu JJ, Herme M, Wickersham J, et al. Understanding the revolving door: individual and structural-level predictors of recidivism among individuals with HIV leaving jail. AIDS Behav. doi:10. 1007/s10461-013-0590-1.

11. Booker CA, Flygare CT, Solomon L, et al. Linkage to HIV care for jail detainees: findings from detention to the first 30 days after release. AIDS Behav. 2012 Dec 6 (Epub ahead of print).

12. Zelenev A, Marcus R, Kopelev A, et al. Patterns of homelessness and implications for HIV health after release from jail. AIDS Behav. 2013 May 9 (Epub ahead of print).

13. Spaulding AC, Messina LC, Kim BI, et al. Planning for success predicts virus suppressed: results of a non-controlled, observational study of factors associated with viral suppression among HIV-positive persons following jail release. AIDS Behav. 2012 Oct 18 (Epub ahead of print).

14. Spaulding AC, Pinkerton SD, Superak H, et al. Cost analysis of enhancing linkages to HIV care following jail: a cost-effective intervention. AIDS Behav. 2012 Nov 9 (Epub ahead of print).

15. The White House Office of National AIDS Policy. National HIV/ AIDS strategy for the United States. July 2010. Available at: http://www.whitehouse.gov/sites/default/files/uploads/NHAS.pdf. 